\title{
Bilingualism and inhibitory control influence statistical learning of novel word forms
}

\section{James Bartolotti *, Viorica Marian, Scott R. Schroeder and Anthony Shook}

Department of Communication Sciences and Disorders, Northwestern University, Evanston, IL, USA

Edited by:

Judith F. Kroll, Penn State University, USA

\section{Reviewed by:}

Tamar H. Gollan, University of

California, USA

Sara Finley, University of Rochester, USA

\section{*Correspondence:}

James Bartolotti, Department of Communication Sciences and

Disorders, Northwestern University, 2240 Campus Drive, Evanston, IL

60208, USA.

e-mail: j-bartolotti@

u.northwestern.edu
We examined the influence of bilingual experience and inhibitory control on the ability to learn a novel language. Using a statistical learning paradigm, participants learned words in two novel languages that were based on the International Morse Code. First, participants listened to a continuous stream of words in a Morse code language to test their ability to segment words from continuous speech. Since Morse code does not overlap in form with natural languages, interference from known languages was minimized. Next, participants listened to another Morse code language composed of new words that conflicted with the first Morse code language. Interference in this second language was high due to conflict between languages and due to the presence of two colliding cues (compressed pauses between words and statistical regularities) that competed to define word boundaries. Results suggest that bilingual experience can improve word learning when interference from other languages is low, while inhibitory control ability can improve word learning when interference from other languages is high. We conclude that the ability to extract novel words from continuous speech is a skill that is affected both by linguistic factors, such as bilingual experience, and by cognitive abilities, such as inhibitory control.

Keywords: language acquisition, statistical learning, bilingualism, inhibitory control, Morse code, Simon task

\section{INTRODUCTION}

Learning a new language is a complex task comprised of mastering novel phonology, vocabulary, and grammar. Acquisition in adults occurs gradually, and even after years of practice many do not achieve native-like levels of pronunciation (Baker and Trofimovich, 2005; Sebastian-Gallés et al., 2006) or grammatical knowledge (Johnson and Newport, 1989; DeKeyser, 2005; MacWhinney, 2005). Even when adults are able to develop adequate vocabulary skills in a new language (Van Hell and Mahn, 1997; Lotto and De Groot, 1998), they often experience initial difficulty forming strong associations between a novel word's lexical form and its meaning (Kroll and Stewart, 1994; Kroll et al., 2002). An important component of learning success is early acquisition of word form, since focusing on learning isolated word forms first can contribute to subsequent learning of words' meanings (Bogaards, 2001; Graf Estes et al., 2007; Mirman et al., 2008; Fernandes et al., 2009). Acquisition of words and their forms has previously been explored by manipulating the learner's input, and it has been shown that variables such as repeated exposure to specific words (Nation, 2001; de Groot, 2006) and reduced speaking rates (Ferguson, 1975) can improve acquisition. In addition, characteristics of the learner may also contribute to successful acquisition. For example, experience with multiple languages has been associated with improved learning of words' form-meaning links (Cenoz and Valencia, 1994; Sanz, 2000; Cenoz, 2003; Keshavarz and Astaneh, 2004; Kaushanskaya and Marian, 2009b), and this learning advantage may arise in part from better initial acquisition of word form. Similarly, inhibitory control (the ability to suppress competing representations and attend to relevant ones) appears to influence learning (Kaushanskaya and Marian, 2009a) and processing (Bartolotti and Marian, 2010) of novel words, and may affect form acquisition. In the present study, we examined how early learning of word forms is affected by characteristics of the learner, including linguistic experience (in the form of bilingualism) and cognitive ability (in the form of inhibitory control).

Learning the forms of novel words is aided by frequent encounters with those words (Osterhout et al., 2006). McLaughlin et al. (2004) found that the best predictor of word familiarity was how frequently that word had appeared during previous instruction. Language learners who study abroad in immersive second language environments encounter specific novel words during daily exposure more often than students who do not, and as a result show greater gains in proficiency (Freed, 1995). The benefits of language immersion arise both from reduced exposure to the native language (Levy et al., 2007; Linck et al., 2009), and from increased exposure to words in the new language (Kojic-Sabo and Lightbown, 1999; Perani et al., 2003). Increased exposure to the new language can strengthen the representations of recently acquired words and introduce the learner to novel words more frequently. Novel words encountered while listening to speech can be acquired incidentally and can increase vocabulary knowledge considerably.

Incidental learning can be accomplished by using the statistical regularities in speech to determine the boundaries of novel word forms. Sounds that co-occur often are likely to comprise part of a single word, whereas rare sound sequences are likely to mark transitions between words. For example, in the phrase "pretty baby," listeners are sensitive to the fact that "pre" followed by " $t y$ " is more likely to occur than " $t y$ " followed by " $b a$," since "pretty" can be 
followed by any number of other words. Both infants and adults are able to track this statistical information and use it to identify novel word forms in an unfamiliar language (Saffran et al., 1996, 1999; Ludden and Gupta, 2000; Theissen and Saffran, 2003; Newport and Aslin, 2004; Kovács and Mehler, 2009).

This ability to learn novel forms in a new language via statistical regularities may be indirectly improved by previous bilingual experience. One of the consequences of bilingualism for cognition is improved phonological working memory (Service et al., 2002; Majerus et al., 2008; Adesope et al., 2010), as a result of acquiring and processing a large vocabulary that encompasses multiple languages. High phonological working memory has been associated with gains in statistical learning of word forms (Misyak and Christiansen, 2007), suggesting that bilingualism may improve statistical learning through its influence on phonological working memory. Phonological working memory can be used to maintain large chunks of speech in memory long enough for the transitions between syllables to be compared. In addition, working memory may help to update the relative frequency of different syllable transitions. Based on the transitional probabilities, likely word candidates can be identified and transferred from working memory to long-term memory. Due to gains in phonological working memory, bilinguals should thus outperform monolinguals in statistical learning of word forms in a novel language.

Learning word forms in a new language may also be influenced by level of inhibitory control. When a new language and a known language conflict, interference from the known language may be particularly detrimental to learning, since the two languages are tightly integrated at early stages of learning (Kroll and Stewart, 1994). Since known languages are highly practiced, they can activate more easily than a new language, resulting in learners over-applying transitional probabilities, pronunciations, or rules from their native language to the new language, even when the two are in conflict (Murphy, 2003). For example, the French possessive "de" occurs before many other French words and thus often marks a word boundary, whereas the same syllable in English is commonly used at the beginning of words and rarely indicates a word boundary. An English-speaking learner of French, then, may not attend to novel words following "de," as this syllable was not a reliable English word boundary cue. By over-applying rules for English word transitions, the learner's acquisition of French word forms may progress at a slower rate. By using inhibitory control to suppress the non-target language, interference from conflicting native-language constructs can be reduced. With less interference, word boundaries in a new language may be easier to learn and speech segmentation may be improved. Indeed, effective inhibitory control has previously been shown to benefit word segmentation when conflicting information present during learning had to be suppressed (Weiss et al., 2010).

To examine the distinct contributions of bilingual experience and inhibitory control on word segmentation, we tested participants who varied in bilingual experience and level of inhibitory control on their ability to learn languages that were based on the International Morse Code. In Morse code, all information is conveyed rhythmically by changes in duration of pure-tone sequences and silences. A benefit of using Morse code is that it is sufficiently difficult to learn and therefore can discriminate learners from non-learners. An additional benefit of using Morse code is that it does not overlap with any languages participants knew and avoids favoring speakers of one language over another. This low overlap with participants' known languages enabled us to create an experimental condition in which interference was low and learning required detecting statistical regularities within the Morse stream, but did not require inhibiting competitive interference from known languages. Because the inhibitory demands were reduced, the low-interference condition allowed us to assess whether bilingual experience has an effect on incidental learning of word forms from speech, independent of inhibitory control ability.

In addition to the low-interference condition, we also designed a second, high-interference condition to assess the influence of inhibitory ability on word segmentation. The words in this second, high-interference condition conflicted with the previously learned words in the low-interference condition. Additionally, a colliding cue to word boundaries that conflicted with the transitional probabilities between words was inserted to create interference within the new language itself (Weiss et al., 2010). Weiss et al. (2010) showed that when two sets of word boundary cues were equally salient, participants with strong inhibitory control were able to selectively attend to one set of cues and learn the words. Although the source of the conflict in their study was within the target language instead of across two languages, inhibitory control may similarly improve learning when the locus of interference is between a known language and a new language. Learning in our high-interference condition depended on selectively attending to one of the two sets of word boundary cues (by inhibiting the other), as in Weiss et al. (2010), but also required participants to suppress competing Morse code words that were previously learned in the low-interference condition. This second, high-interference condition therefore enabled us to examine the influence of inhibitory ability on word segmentation in contexts where learners have to reduce interference from conflicting linguistic information both within and across languages.

To summarize, in the present study, we examined the distinct contributions of bilingual experience and inhibitory control on word segmentation. Participants who varied in bilingual experience and level of inhibitory control were taught Morse code words first in a low-interference condition and then in a highinterference condition. The low-interference condition placed few demands on inhibition; in this condition, high bilingual experience was expected to contribute to successful word segmentation. The high-interference condition placed high demands on inhibition; in this condition, inhibitory ability was expected to promote successful word segmentation.

\section{MATERIALS AND METHODS PARTICIPANTS}

Twenty-four Northwestern University students (Mean age $=$ 21.6 years, $\mathrm{SD}=2.23$ ) participated for course credit. All participants provided informed consent in accordance with the Northwestern University IRB. Participants completed the Language Experience and Proficiency Questionnaire (LEAP-Q; Marian et al., 2007) to provide information about language proficiency, age of 
acquisition, and frequency of language use. Languages represented as participants' dominant language included English $(N=20)$, Korean $(N=1)$, and Chinese $(N=1)$. Second languages reported included Spanish $(N=7)$, Chinese $(N=4)$, English $(N=2)$, French $(N=1)$, Gujarati $(N=1)$, Korean $(N=1)$, and Tamil $(N=1)$; five participants reported no meaningful second language experience. A breakdown of language knowledge by group is provided in Table A1 in the Appendix. Based on participants' reported L2 proficiency, L2 age of acquisition, and L2 frequency of use, a composite score of bilingual experience was computed. L2 proficiency, L2 age of acquisition, and L2 frequency of use were transformed to $Z$-scores for each participant based on the group mean and SD, and the average of these three scores was used as a composite measure of overall bilingual experience. Participant characteristics are presented in Table $\mathbf{1}$.

A version of the Simon task (Simon and Small, 1969) was used to assess participants' inhibitory control ability. Median splits were used to separate participants into high/low bilingual experience groups based on the bilingual experience composite, and strong/weak inhibitory control based on the size of the Simon effect (median: $33.24 \mathrm{~ms}$ ). High and low bilingual experience groups did not differ in age, performance IQ (block design and matrix reasoning subtests of the Weschler Abbreviated Scale of Intelligence; PsychCorp, 1999), working memory (digit span subtest of the Comprehensive Test of Phonological Processing; Wagner et al., 1999), or inhibitory control ability. Strong and weak inhibitory control groups did not differ in age, performance IQ, working memory, L2 proficiency, L2 age of acquisition, or L2 frequency of use.

Inhibitory control as assessed by the Simon task was not correlated with the bilingual experience composite $(p=0.50)$ or any of its components (L2 proficiency, $p=0.09$; L2 age of acquisition, $p=0.84$; L2 frequency of use, $p=0.73$ ), allowing the effects of bilingual experience and inhibitory control on learning to be considered separately. The lack of a correlation was not unexpected; bilingual advantages in inhibitory control are frequently observed in children (Bialystok and Martin, 2004; Carlson and Meltzoff, 2008) and older adults (Bialystok et al., 2004; Salvatierra and Rosselli, 2011), but results are mixed in younger adults who are in their cognitive prime. In particular, certain tasks of executive functioning, such as Stroop and the Attentional Network Test, commonly reveal bilingual advantages in young adults (Bialystok et al., 2008; Costa et al., 2008; Tao et al., 2011). Other executive functioning tasks, such as the Simon task, are reliable predictors of word segmentation in the presence of conflicting cues (Weiss et al., 2010), but do not appear to be robustly driven by bilingual experience (Bialystok et al., 2005; Bialystok, 2006; Prior and MacWhinney, 2010; Blumenfeld and Marian, 2011; Hilchey and Klein, 2011). In the present study, because variability in bilingual experience was not related to variability in inhibitory control, it was possible to examine the separate effects of these two factors on learning to segment words in a novel language.

\section{MATERIALS}

Two artificial languages were created based on the International Morse Code alphabet. In Morse code, letters are composed of combinations of short tones, or "dots" ( $440 \mathrm{~Hz}$ for $100 \mathrm{~ms})$ and long tones, or "dashes" (440 Hz for $300 \mathrm{~ms}$ ). Two letters (E / ./ and T $/-/$ ) are made up of a single tone each, and four letters (A / . - /, I $/$. ./, $\mathrm{N} /-$./, and $\mathrm{M} /--/$ ) are made up of two tones in sequence. When a single letter contained two tones, the tones were separated by a short $100 \mathrm{~ms}$ pause. When multiple letters were combined to form a single word, the letters were separated by a longer $300 \mathrm{~ms}$ pause, so that the multi-tone letters (i.e., I, A, N, and M) could still be perceived as distinct groupings (without this distinction in pause lengths, the letter sequence "ET" would be indistinguishable from the single letter "A"). By using all six letters (A, E, I, N, M, $\mathrm{T})$, three words were created for each of two languages such that the length of each word was a constant $1100 \mathrm{~ms}$, and no letter was used twice (See Figure 1).

Morse code training streams were created for each language with two restrictions: A word could not immediately follow itself, and each word was followed by the other two words an equal number of times. Since the first letter of each word perfectly predicted the second letter, transitional probability within words was

Table 1 | Means and SD (in parentheses) for participant characteristics.

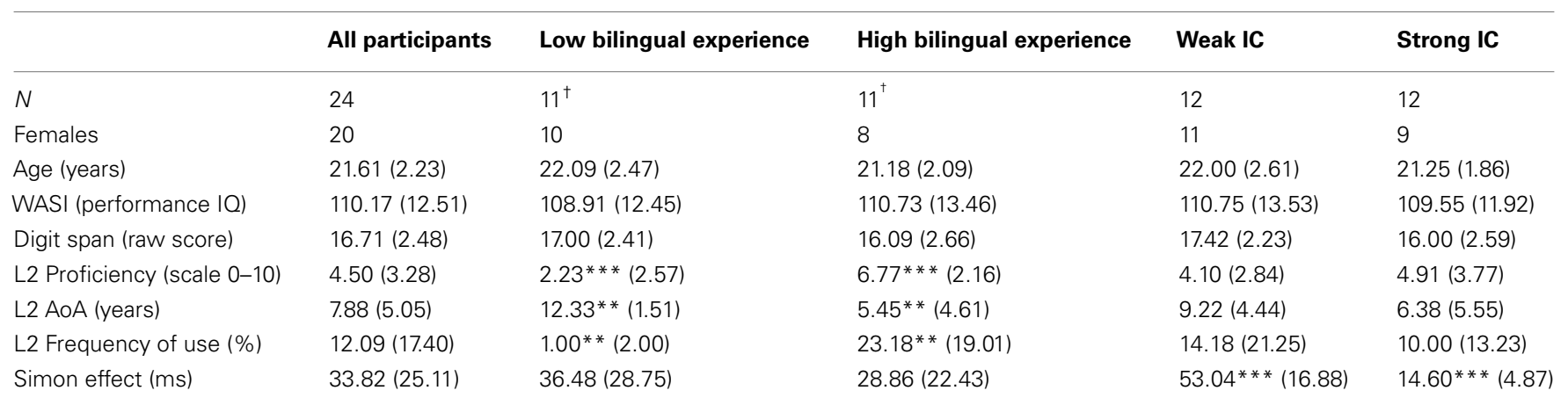

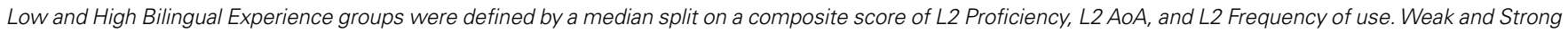
Inhibitory Control groups were defined based on a median split of the size of the Simon effect.

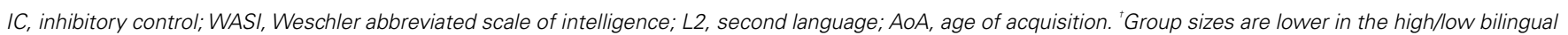
experience comparison because language data were not available for two participants. ${ }^{* *} p<0.01$ between groups, ${ }^{* * *} p<0.001$ between groups 
a constant 1.0. Since each word could be followed by either of the two other words, the between-word transitional probability was a constant 0.5 . The training stream in the low-interference condition had a 300-ms long pause inserted between words, identical to the long pause that separated letters within a single word. To learn the words, participants would have to attend to the transitional probabilities within and between words. For example, the continuous stream TAEMTANI can be segmented as TAEM-TA-NI based on the transitional probabilities between letters (see Figure 2A). In contrast, in the high-interference condition, the long pause between words was replaced with a $100 \mathrm{~ms}$ short pause. The $300 \mathrm{~ms}$ long pause that remained within words could be used as a salient grouping cue to identify words in the stream.

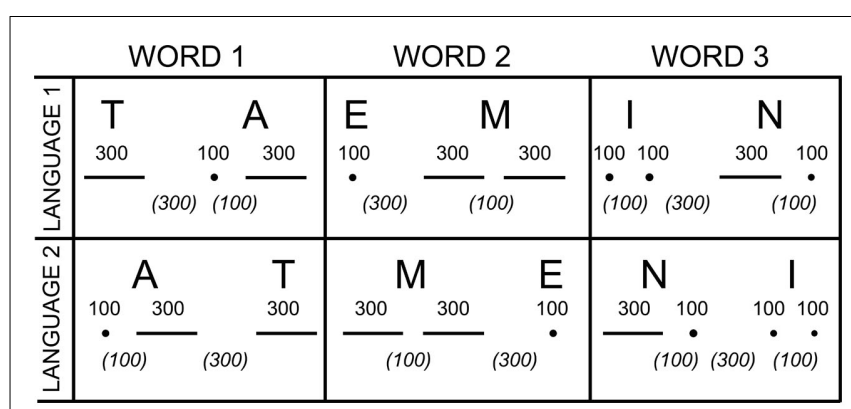

FIGURE 1 |The Morse code words used in the two languages. Long tones, or dashes, are $300 \mathrm{~ms}$ long, and short tones, or dots, are $100 \mathrm{~ms}$ long. Numbers in parentheses indicate the length of the pause, either 100 or $300 \mathrm{~ms}$. Short pauses separate tones within a letter, and long pauses separate letters within a word.

\section{A LOW INTERFERENCE

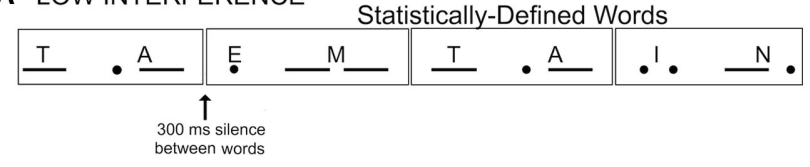 \\ B HIGH INTERFERENCE Statistically-Defined Words

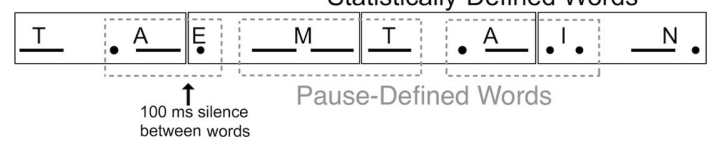

FIGURE 2 | Morse code listening streams in the low and

high-interference conditions. The dots and dashes represent short $(100 \mathrm{~ms})$ and long $(300 \mathrm{~ms})$ tones respectively, while the short and long gaps represent silences of 100 and 300 ms respectively. In the low-interference condition (A), words are marked by statistical probabilities between letters (the transitional probability within words is $100 \%$, e.g., $T$ is always followed by $\mathrm{A}$, but the transitional probability between words is $50 \%$, e.g., A is followed by either $E$ or I). In the high-interference condition (B), the gap between words is reduced, and the statistically defined words (TA, EM, IN) compete with words defined by the long pauses ( $A E, M T, A$, as well as MI, NT, NE). Each participant was exposed to both the low- and high-interference conditions. The order of the two conditions was fixed, with the low-interference condition always occurring first, but the language used in each condition was counterbalanced across subjects. In the example above, the same language is shown in both the low-interference condition and the high-interference conditions in order to highlight the difference between conditions.
If participants ignored the different pause lengths, they would still be able to learn the words based on the transitional probabilities, as in the low-interference condition. If instead participants used the pause lengths as a cue to word boundaries, they would learn a different set of words than those defined by the transitional probabilities. There were thus two colliding cues to word boundary: the between-word transitional probabilities (as in the low-interference condition), and the pause-based cues (see Figure 2B). To learn the words, participants would have to inhibit one of the two word boundary cues and attend to the other.

\section{PROCEDURE}

The Morse code language associated with each condition was counterbalanced across participants, so that half of the participants heard Language 1 for the low-interference condition and Language 2 for the high-interference condition, while the other half of the participants heard Language 2 for the low-interference condition and Language 1 for the high-interference condition. The order of the two conditions was fixed, with all participants completing the low-interference condition first, followed by the high-interference condition. This was done to ensure that no previously learned Morse code words could compete with targets during the low-interference condition. Learned words would then have to be inhibited during the following high-interference condition, increasing the inhibitory demands of the high-interference condition.

At the beginning of each learning condition, participants were instructed to listen to a series of tones and were told that they would be tested on information about the tones later. Participants wore headphones and listened to the Morse code stream over three blocks, each $4 \mathrm{~min}$ and $12 \mathrm{~s}$ long. Participants received a $1-\mathrm{min}$ silent break between blocks.

Immediately after the third training block, participants were tested on their knowledge of the language with a 12-item twoalternative forced-choice task. Participants were instructed to indicate which of two Morse code words was more familiar by pressing the "1" (first word) or "9" (second word) key on a computer keyboard. Word pairs were presented with a 1-s pause between words, and a 4-s pause between trials. Each of the three words was presented in four trials: twice before and twice after two different part-words. Part-words were created by concatenating the second letter from one word with the first letter of another word, and had appeared in the listening stream half as often as the actual words. In the high-interference condition, the part-words were words that could have been learned by using pause-based cues instead of statistical cues. Accuracy scores were obtained and normalized to chance performance, with a score of 0 indicating 6 out of 12 correct (where correct meant selecting the statistically defined word). Positive scores indicated learning of the statistical probabilities. In the high-interference condition, negative scores indicated learning of the pause-based rules.

All participants also completed a visual Simon task (Simon and Small, 1969; Weiss et al., 2010) to index inhibitory control. Participants viewed blue and brown rectangles that appeared on the left, right, or center of a computer screen and selected a response based on the item's color, while ignoring its location. The instructions 
were to press a blue button on the left side of the keyboard if the rectangle was blue, or to press a brown button on the right side of the keyboard if the rectangle was brown. In Congruent trials, the stimulus and the response were on the same side (e.g., a blue rectangle on the left side of the screen). In Incongruent trials, stimulus and response were on opposite sides (e.g., blue rectangle on the right side of the screen). In Neutral trials, the stimulus appeared in the center of the screen. Congruent, Incongruent, and Neutral trials appeared in an equal ratio (42 trials each, 126 total). A single trial involved (1) a fixation cross for $350 \mathrm{~ms}$, (2) a blank screen for $150 \mathrm{~ms}$, (3) a colored rectangle for $1500 \mathrm{~ms}$, (4) in the event of an error, a red "X" as feedback for $1500 \mathrm{~ms}$, and (5) a blank screen for an $850 \mathrm{~ms}$ inter-trial interval. All participants completed a practice session before the actual task. The Simon effect was calculated by subtracting reaction time on Congruent trials from reaction time on Incongruent trials. A small Simon effect indicates better ability to ignore the inconsistent location cue, and strong inhibitory control.

\section{RESULTS}

\section{WORD LEARNING IN THE LOW-INTERFERENCE CONDITION}

When interference during learning was low, bilingual experience positively influenced word learning ability, whereas level of inhibitory control did not influence learning (Figure 3). The high bilingual experience group performed significantly better than chance $(M=2.41, \mathrm{SD}=2.01), t(10)=3.98, p<0.01$, while the low bilingual experience group did not differ from chance $(M=1.09, \mathrm{SD}=2.34), p=0.15$, indicating that the high bilingual experience group was able to learn the Morse code words. The same pattern of results was observed when each factor in the bilingual experience composite was considered separately, that is, when participants were divided into two groups based on median splits in L2 proficiency, L2 age of acquisition, or L2 frequency of use. Both the strong $(M=1.79, \mathrm{SD}=2.46), t(11)=2.52, p<0.05$, and weak $(M=1.92, \mathrm{SD}=1.98), t(11)=3.36, p<0.01$, inhibitory control groups performed above chance, indicating that they were able to learn the Morse code language.

Learning was not correlated with bilingual experience, $p=0.76$, L2 age of acquisition, $p=0.40$, or L2 frequency of use, $p=0.55$, but was marginally correlated with L2 proficiency, $r=0.40, p=0.06$

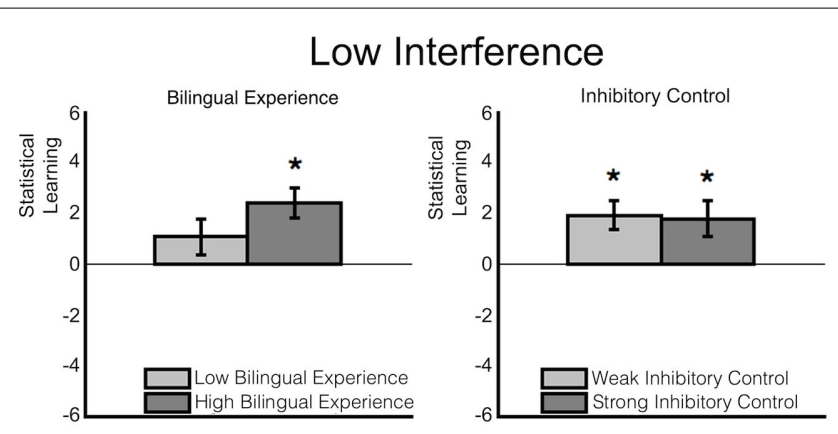

FIGURE 3 | Effects of second language proficiency and inhibitory control on learning the new language in the low-interference condition. (Asterisks indicate a significant difference from chance, alpha of 0.05. Error bars indicate $1 \mathrm{SE})$.
(Figure 4). Inhibitory control ability was not correlated with learning, $p=0.37$.

\section{WORD LEARNING IN THE HIGH-INTERFERENCE CONDITION}

When interference during learning was high, strong inhibitory control increased word learning, but bilingual experience did not (Figure 5). In this condition, positive scores above chance indicate learning of the words based on statistical cues, while negative scores below chance indicate learning of the words based on pause cues. Participants with strong inhibitory control performed significantly below chance, indicating that they learned according to the pause cues $(M=-1.18, \mathrm{SD}=1.60), t(10)=-2.45, p<0.05$, while participants with weak inhibitory control did not differ from chance $(M=0.58, \mathrm{SD}=1.73), p=0.27$. No consistent pattern of learning was observed when bilingual experience was considered; neither the high bilingual experience group $(M=0.18, \mathrm{SD}=2.14$; $p=0.78)$, nor the low bilingual experience group $(M=-0.55$,

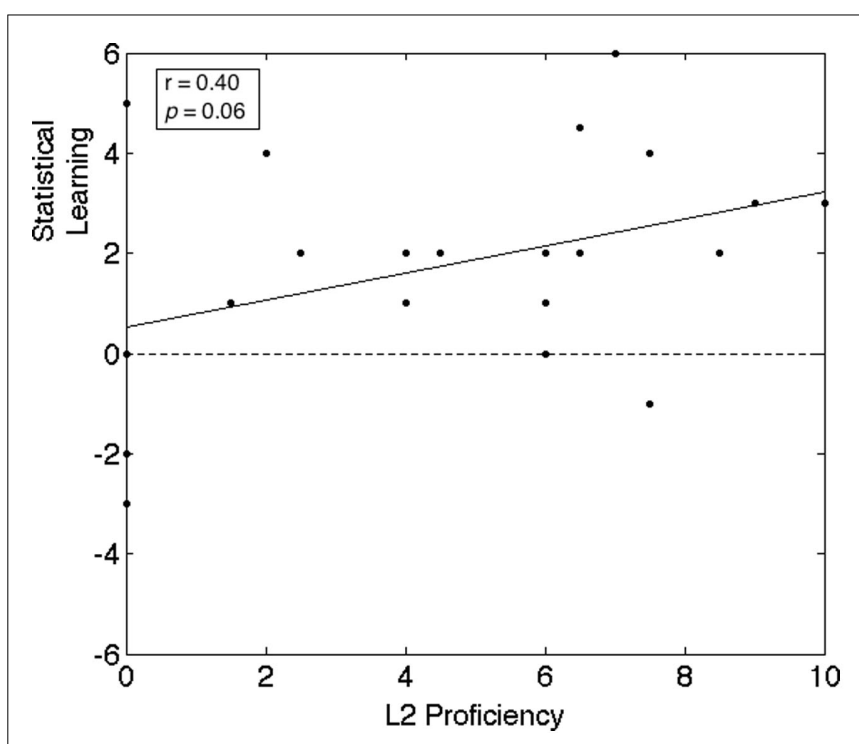

FIGURE 4 | Relationship between second language proficiency and learning of word forms in the low-interference condition.

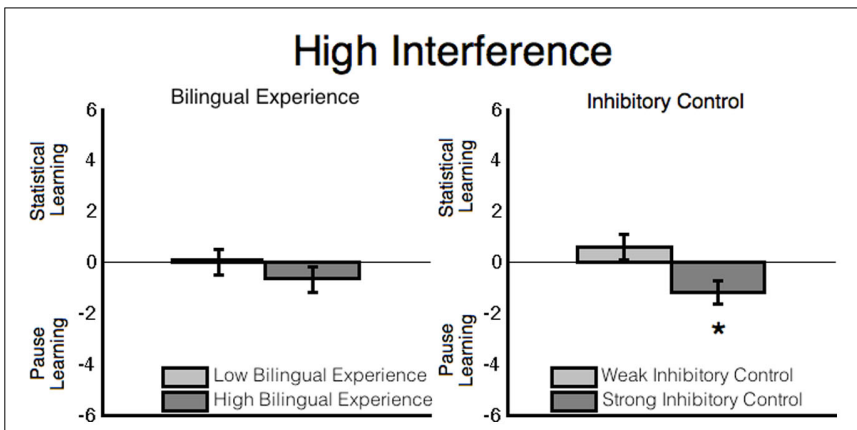

FIGURE 5 | Effects of second language proficiency and inhibitory control on learning the new language in the high-interference condition. Positive scores indicate learning of statistical cues and negative scores indicate learning of pause cues. (Asterisks indicate a significant difference from chance, alpha of 0.05. Error bars indicate $1 \mathrm{SE}$ ). 
$\mathrm{SD}=1.57), p=0.28$ differed from chance. In addition, when each factor in the bilingual experience composite was considered separately, no group performed better than chance.

Inhibitory control was correlated with learning success, $r=0.47, p<0.05$ (Figure 6), while bilingual experience, $p=0.94$, L2 proficiency, $p=0.99$, L2 age of acquisition, $p=0.86$, and L2 frequency of use, $p=0.75$ were not correlated with learning.

\section{DISCUSSION}

Learning words in a new language is a multi-step process involving the acquisition of new word forms and of mapping these acquired word forms to meaning. While previous research suggests that bilingualism improves learning of form-meaning mappings in another language (Cenoz and Valencia, 1994; Sanz, 2000; Cenoz, 2003; Keshavarz and Astaneh, 2004; Kaushanskaya and Marian, 2009b), in the current study we found that bilingual experience can improve acquisition of word forms alone when interference between languages is low. In addition, we showed that inhibitory control promoted successful word segmentation when there were competing cues to word boundaries both within and across languages. Successful acquisition of word forms has previously been shown to be one factor that contributes to later stages of word learning (e.g., mapping form to meaning, Graf Estes et al., 2007; Mirman et al., 2008) and increases the rate at which vocabulary is expanded (Bogaards, 2001). During natural language learning, both bilingual experience and inhibitory control may contribute in different degrees to early acquisition of novel word forms (depending on the characteristics of the language to be learned), which may benefit the process of learning a novel language.

High bilingual experience was associated with successful segmentation of Morse code word forms from a continuous auditory stream with consistent cues to word boundaries. In order to learn the word forms in the low-interference condition, participants had to analyze the transitional probabilities between sounds and extract the most commonly occurring sequences. This ability to

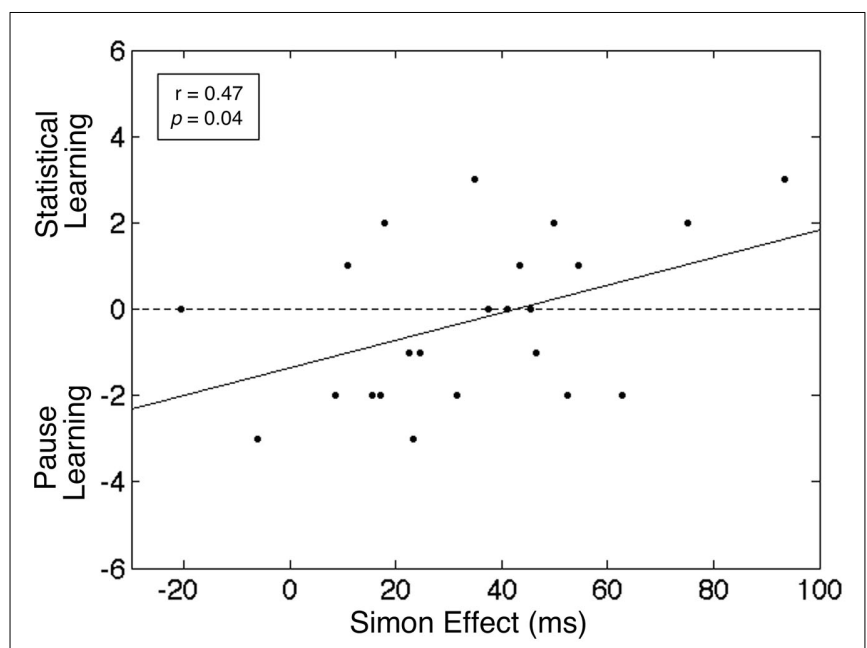

FIGURE 6 | Relationship between inhibitory control (assessed by the Simon task) and learning of word forms in the high-interference condition. analyze probabilities may depend in part on phonological working memory, which has previously been associated with improved statistical learning (Misyak and Christiansen, 2007). Extensive bilingual experience has been associated with gains in phonological working memory (Service et al., 2002; Majerus et al., 2008; Adesope et al., 2010), which may have contributed to bilinguals' ability to learn the words. It is possible that bilinguals used working memory more effectively than monolinguals to maintain large chunks of the auditory sequence for statistical analysis. Working memory could also contribute by updating the frequencies of specific transitions over time, and by facilitating the transfer of newly detected words to long-term memory. By effectively applying phonological working memory to the statistical learning task, bilinguals may have been able to better extract and retain novel word forms.

Statistical learning is itself a measure of implicit learning ability, as participants are typically not aware of having consciously learned any of the words. Bilinguals' improved performance on the statistical learning task is thus consistent with observed bilingual advantages on language learning tasks that rely heavily on implicit learning (Klein, 1995; Kovács and Mehler, 2009). For example, Nation and McLaughlin (1986) found that proficiency in multiple languages improved learning of an artificial grammar when participants did not explicitly attend to the grammatical rules, but acquired them implicitly during the course of learning novel words. As a consequence of acquiring the words and grammar of multiple languages, bilinguals may develop a more effective implicit learning mechanism than monolinguals. This increased efficiency could contribute to bilinguals' improved incidental learning of word forms while listening to speech.

In contrast to bilinguals' performance in the low-interference condition, in the high-interference condition, bilingual experience had no effect on word segmentation success. One possibility for the lack of learning is that both those with low and those with high bilingual experience may have been unable to consistently attend to either the statistical or pause-based cues. If participants shifted attention between the two cues during training, then at test neither the statistically defined words nor the pause-defined words would be more familiar and performance would remain at chance. Alternatively, it may be that bilingual experience improves efficiency of integrating multiple cues. Given that most languages use correlated cues to word segmentation and relatively few contrasting cues (Christiansen et al., 2005; Sahni et al., 2010), when cues are not correlated (as was the case in the high-interference condition), this ability to integrate cues may be a drawback. Learning in the high-interference condition required that participants attend to a single set of cues and suppress the other; bilinguals may have either been unable to attend to either cue, or attended to and integrated both cues.

Participants with strong inhibitory control were able to selectively attend to a single set of cues in the high-interference condition, suggesting that inhibitory control can also contribute to word segmentation ability. In the high-interference condition, conflict occurred due to both incongruent word boundaries between the two Morse code languages across blocks, and colliding cues to word boundary within the listening stream. Learning word boundaries in the high-interference condition required one to 
ignore recently learned transitional probabilities from the lowinterference condition, and to selectively attend to one of the two colliding cues to word boundaries in the high-interference condition. Successful learning could be accomplished by inhibiting irrelevant information in memory (previous transitional probabilities) and in the auditory stream (one of the two colliding cues to word boundaries).

The overall pattern of learning in the high-interference condition suggests that participants with strong inhibitory control suppressed the statistical information and relied on pause lengths between letters to segment words. One possibility is that pause lengths were a more salient cue than the transitional probabilities, making them easier to learn. However, if the pause boundaries in the auditory stream had been much more salient than the statistical boundaries, we might have expected all groups to pick up on this cue and learn the pause-defined words. In a previous study using colliding statistical and pause-based cues to word segmentation, when the pause cue was made more salient (by manipulating its length), participants overwhelmingly were able to learn the pause-defined words (Weiss et al., 2010). In our colliding cue condition we saw evidence of learning only in the strong inhibitory control group, which suggests that the pause cues were learnable, but that the statistical cues were close enough in saliency to interfere with learning in the weak inhibitory control group. The tendency of the strong inhibitory control group to segment words according to the pauses may reflect a strategy that minimized sources of interference. Recall that in the high-interference condition, pauses conflicted with transitional probabilities, while the transitional probabilities conflicted with both the pauses and the transitional probabilities from the low-interference condition. The pauses thus directly competed with only one source, while the statistical boundaries directly competed with two sources. The participants with strong inhibitory control may have been sensitive to this difference and applied inhibition in a way that maximized cue salience, by suppressing all statistical cues and engaging learning of the pauses between words.

To summarize, our findings suggest that experience with a second language helped learners identify novel words by attending to statistical regularities in the signal, whereas inhibitory control helped learners identify novel words by suppressing conflicting language knowledge and focusing attention on the meaningful aspects of a novel language. To date, there has often been considerable attention paid to how bilingual experience may impact executive functioning or its subcomponents, including response suppression, inhibitory control, task switching, and task monitoring (Bialystok and Martin, 2004; Bialystok et al., 2004; Bialystok et al., 2008; Carlson and Meltzoff, 2008; Costa et al., 2008, 2009; Hernández et al., 2010; Prior and MacWhinney, 2010; Soveri et al., 2010; Salvatierra and Rosselli, 2011; Tao et al., 2011). While bilingual advantages are typically more robust in young children or older adults (see Hilchey and Klein, 2011), they can be observed in young adults, particularly on tasks that require context monitoring (Costa et al., 2008, 2009; Prior and MacWhinney, 2010; Tao et al., 2011). The link between bilingualism and executive functioning is thought to stem from bilinguals' need to control language access. Both of a bilingual's languages remain active when only one is present in the immediate linguistic context, requiring the bilingual to monitor the language in use, selectively attend to the target language, and inhibit the non-target language. Constant training of the executive functions recruited to direct attention during language processing may improve executive functioning in other domains. However, in young adults, inhibitory control ability appears to be influenced by other factors besides bilingualism as well (Bialystok et al., 2005; Bialystok, 2006; Prior and MacWhinney, 2010; Blumenfeld and Marian, 2011; Hilchey and Klein, 2011). In the present study, we were able to examine the differential effects of bilingual experience and inhibitory control on learning to segment words in two Morse code languages that differed in the strength of conflicting information. By examining acquisition of word forms in these different learning contexts, we have shown that linguistic and cognitive characteristics of the learner can affect success at an early stage of language learning, specifically, during word form acquisition.

One potential limitation of the current study is that the Morse code languages that participants learned were composed of pure tones that do not closely resemble natural speech. The choice to use pure-tone stimuli was made in order to limit transfer of prior knowledge during learning. Bilinguals have been shown to readily transfer words and grammatical structures from languages they already know when it can facilitate learning (Cenoz, 1997; Murphy, 2003), and using Morse code stimuli avoided confounding bilingual experience with increased transfer of prior language knowledge. By using word forms based on Morse code, we were able to control participants' prior experience with the target language, and since language backgrounds were unlikely to confer a benefit, we were able to specifically target the effects of bilingual experience and inhibitory control on sequence learning. It is important that future research extends the findings from the current study to natural language learning, as there is reason to believe that the processes involved in learning the Morse code words and in natural language acquisition overlap. The ability to extract information from a continuous stream through statistical learning mechanisms appears to be a domain-general skill, and has been shown to affect sequence learning of musical tones (Saffran et al., 1999), visual shapes (Kirkham et al., 2002), and tactile stimuli (Conway and Christiansen, 2005), as well as that of non-word syllables (Saffran et al., 1996; Ludden and Gupta, 2000; Theissen and Saffran, 2003; Newport and Aslin, 2004; Kovács and Mehler, 2009). In addition, sequence learning skill has been shown to correlate positively with second language learning success in a classroom setting (Ettlinger et al., 2011), suggesting that word segmentation ability can contribute to natural language learning.

It is likely that previous bilingual experience and inhibitory control ability work simultaneously to promote learning, but their relative influences may depend on the relationship between known languages and the target language. For example, bilingualism may be a more important factor in learning word forms when the target language contains novel, non-overlapping features, such as the distinct writing systems between English and Chinese. Inhibitory control may be more important in promoting learning when the two languages conflict, such as the shared Roman alphabet but contrasting letter to phoneme mappings between English and French. As each case of novel language learning contains non-overlapping and conflicting components, both bilingual 
experience and inhibitory control are likely to be contributing factors to early acquisition of novel word forms, though their specific influences will depend on the characteristics of the novel language and already known languages.

In conclusion, the present study extends previous research on the role of linguistic experience and inhibitory control in later stages of language learning to early stages of language acquisition. While previous work has shown that linguistic experience and inhibitory control impact acquisition of and access to formmeaning mappings (Cenoz and Valencia, 1994; Sanz, 2000; Cenoz, 2003; Keshavarz and Astaneh, 2004; Kaushanskaya and Marian, 2009a,b; Bartolotti and Marian, 2010), we propose that linguistic experience and inhibitory control also influence initial acquisition of word form. Moreover, our results suggest that linguistic experience and inhibitory control may affect learning in different ways, depending on the relationship between the language to be learned

\section{REFERENCES}

Adesope, O. O., Lavin, T., Thompson, T., and Ungerleider, C. (2010). A systematic review and metaanalysis of the cognitive correlates of bilingualism. Rev. Educ. Res. 80, 207-245.

Baker, W., and Trofimovich, P. (2005). Interaction of native- and secondlanguage vowel system(s) in early and late bilinguals. Lang. Speech 48(Pt 1), 1-27.

Bartolotti, J. V., and Marian, V. (2010). "Linguistic control in monolingual and bilingual language learners," in Proceedings of the 32nd Annual Conference of the Cognitive Science Society, eds S. Ohlsson and R. Catrambone (Austin, TX: Cognitive Science Society), 532 .

Bialystok, E. (2006). Effect of bilingualism and computer video game experience on the Simon task. Can. J. Exp. Psychol. 60, 68-79.

Bialystok, E., Craik, F., and Luk, G. (2008). Cognitive control and lexical access in younger and older bilinguals. J. Exp. Psychol. Learn. Mem. Cogn. 34, 859-873.

Bialystok, E., Craik, F. I. M., Klein, R., and Viswanathan, M. (2004). Bilingualism, aging, and cognitive control: evidence from the Simon task. Psychol. Aging 19, 290-303.

Bialystok, E., and Martin, M. M. (2004). Attention and inhibition in bilingual children: evidence from the dimensional change card sort task. Dev. Sci. 7, 325-339.

Bialystok, E., Martin, M. M., and Viswanathan, M. (2005). Bilingualism across the lifespan: the rise and fall of inhibitory control. Int. J. Biling. 9, 103-119.

Blumenfeld, H. K., and Marian, V. (2011). "Bilingualism influences perceptual inhibition more than stimulus-response inhibition," in
Proceedings of the 33rd Annual Conference of the Cognitive Science Society, eds L. Carlson, C. Hölscher, and T. Shipley (Austin, TX: Cognitive Science Society), 3009.

Bogaards, P. (2001). Lexical units and the learning of foreign language vocabulary. Stud. Second Lang. Acquistion 23, 321-343.

Carlson, S., and Meltzoff, A. N. (2008). Bilingual experience and executive functioning in young children. Dev. Sci. 11, 282-298.

Cenoz, J. (1997). "The influence of bilingualism on multilingual acquisition: some data from the Basque Country," in I Simposio Internacional sobre o Bilingüismo: Comunidades e individuos bilingües, Universidade de Vigo, Vigo, 278-287.

Cenoz, J. (2003). The additive effect of bilingualism on third language acquisition: a review. Int. J. Biling. 7, 71-87.

Cenoz, J., and Valencia, J. F. (1994). Additive trilingualism: evidence from the Basque country. Appl. Psycholinguist. 15, 195-207.

Christiansen, M. H., Conway, C. M., and Curtin, S. (2005). "Multiple-cue integration in language acquisition: a connectionist model of speech segmentation and rule-like behavior," in Language Acquisition, Change and Emergence: Essay in Evolutionary Linguistics, eds J. W. Minett and W. S. Y. Wang (Hong Kong: City University of Hong Kong Press), 205-249.

Conway, C. M., and Christiansen, M. H. (2005). Modality-constrained statistical learning of tactile, visual, and auditory sequences. J. Exp. Psychol. Learn. Mem. Cogn. 31, 24-39.

Costa, A., Hernández, M., CostaFaidella, J., and Sebastián-Gallés, N. (2009). On the bilingual advantage

and prior linguistic knowledge. The current study suggests that internal factors such as linguistic experience and cognitive ability can interact with external factors such as a new language's structure and its conflict with known languages to influence early components of language learning. Future work will need to examine how these interactions influence later stages of language learning. Investigating how internal and external factors interact within the learning process is essential for understanding ultimate language attainment.

\section{ACKNOWLEDGMENTS}

This research was funded in part by grants NICHD 1R01HD059858 and NSF BCS-0418495 to the second author. The authors would like to acknowledge Sarah Chabal, Jen Krizman, Natalia Daniel, and Vivian Chang for comments on an earlier draft of this paper.

in conflict processing: now you see it, now you don't. Cognition 113 135-149.

Costa, A., Hernández, M., and Sebastián-Gallés, N. (2008). Bilingualism aids conflict resolution: evidence from the ANT task. Cognition 106, 59-86.

de Groot, A. M. B. (2006). Effects of stimulus characteristics and background music on foreign language vocabulary learning and forgetting. Lang. Learn. 56, 463-506.

DeKeyser, R. M. (2005). What makes learning second-language grammar difficult? A review of issues. Lang. Learn. 55, 1-25.

Ettlinger, M., Morgan-Short, K. Faretta-Stutenberg, M., and Wong, P. C. M. (2011). The relationship between artificial and natural language learning. 85th Annual Meeting of the Linguistic. Society of America, Pittsburgh.

Ferguson, C. (1975). "Sound patterns in language acquisition," in Developmental Psycholinguistics: Theory and Applications, Georgetown University Round Table on Languages and Linguistics, ed. D. P. Daniel (Washington, DC: Georgetown University Press), 1-16.

Fernandes, T., Kolinsky, R., and Ventura, P. (2009). The metamorphosis of the statistical segmentation output: lexicalization during artificial language learning. Cognition 112, 349-366.

Freed, B. F. (ed.). (1995). Second Language Acquisition in a Study Abroad Context. Philadelphia: John Benjamins.

Graf Estes, K., Evans, J. L., Alibali, M. W. and Saffran, J. R. (2007). Can infants map meaning to newly segmented words? Statistical segmentation and word learning. Psychol. Sci. 18, 254-260.
Hernández, M., Costa, A., Fuentes, L. J., Vivas, A. B., and SebastiánGallés, N. (2010). The impact of bilingualism on the executive control and orienting networks of attention. Biling. (Camb. Engl.) 13, 315-325.

Hilchey, M. D., and Klein, R. M. (2011). Are there bilingual advantages on nonlinguistic interference tasks? Implications for the plasticity of executive control processes. Psychon. Bull. Rev. 18, 625-658.

Johnson, J. S., and Newport, E. L. (1989). Critical period effects in second language learning: the influence of maturational state on the acquisition of English as a second language. $\operatorname{Cog} n$. Psychol. 21, 60-99.

Kaushanskaya, M., and Marian, V. (2009a). Bilingualism reduces native-language interference during novel-word learning. J. Exp. Psychol. Learn. Mem Cogn. 35, 829-835.

Kaushanskaya, M., and Marian, V. (2009b). The bilingual advantage in novel word learning. Psychon. Bull. Rev. 16, 705-710.

Keshavarz, M. H., and Astaneh, H. (2004). The impact of bilinguality on the learning of English vocabulary as a foreign language (L3). Int. J. Biling. Educ. Biling. 7, 295-302.

Kirkham, N. Z., Slemmer, J. A., and Johnson, S. P. (2002). Visual statistical learning in infancy: evidence for a domain-general learning mechanism. Cognition 83, B35-B42.

Klein, E. (1995). Second versus third language acquisition: is there a difference? Lang. Learn. 45, 419-465.

Kojic-Sabo, I., and Lightbown, P. M. (1999). Students' approaches to vocabulary learning and their relationship to success. Mod. Lang. J. 83, 176-192. 
Kovács, A. M., and Mehler, J. (2009). Flexible learning of multiple speech structures in bilingual infants. Science 325, 611-612.

Kroll, J. F., Michael, E., Tokowicz, N., and Dufour, R. (2002). The development of lexical fluency in a second language. Second Lang. Res. 18, 137-171.

Kroll, J. F., and Stewart, E. (1994). Category interference in translation and picture naming: evidence for asymmetric connections between bilingual memory representations. J. Mem. Lang. 33, 149-174.

Levy, B. J., McVeigh, N. D., Marful, A., and Anderson, M. C. (2007). Inhibiting your native language: the role of retrieval-induced forgetting during second-language acquisition. Psychol. Sci. 18, 29-34.

Linck, J. A., Kroll, J. F., and Sunderman, G. (2009). Losing access to the native language while immersed in a second language: evidence for the role of inhibition in secondlanguage learning. Psychol. Sci. 20, 1507-1515.

Lotto, L., and De Groot, A. M. B. (1998). Effects of learning method and word type on acquiring vocabulary in an unfamiliar language. Lang. Learn. 48, 31-69.

Ludden, D., and Gupta, P. (2000). "Zen in the art of language acquisition: statistical learning and the less is more hypothesis," in Proceedings of the 22nd Annual Conference of the Cognitive Science Society, eds L. R. Gleitman and A. K. Joshi (Hillsdale, NJ: Erlbaum), 812-817.

MacWhinney, B. (2005). "A unified model of language acquisition," in Handbook of Bilingualism: Psycholinguistic Approaches, eds J. F. Kroll and A. M. B. De Groot (Oxford: Oxford University Press), 49-67.

Majerus, S., Poncelet, M., Van der Linden, M., and Weekes, B. S. (2008). Lexical learning in bilingual adults: the relative importance of shortterm memory for serial order and phonological knowledge. Cognition 107, 395-419.
Marian, V., Blumenfeld, H. K., and Kaushanskaya, M. (2007). The language experience and proficiency questionnaire (LEAP-Q): assessing language profiles in bilinguals and multilinguals. J. Speech Lang. Hear. Res. 50, 940-967.

McLaughlin, J., Osterhout, L., and Kim, A. (2004). Neural correlates of second-language word learning: minimal instruction produces rapid change. Nat. Neurosci. 7, 703-704.

Mirman, D., Magnuson, J. S., Graf Estes, K., and Dixon, J. A. (2008). The link between statistical segmentation and word learning in adults. Cognition 108, 271-280.

Misyak, J. B., and Christiansen, M. H. (2007). Extending statistical learning farther and further: longdistance dependencies, and individual differences in statistical learning and language," in Proceedings of the 33rd Annual Meeting of the Cognitive Science Society, eds D. S. McNamara and J. G. Trafton (Austin, TX: Cognitive Science Society), 1307-1312.

Murphy, S. (2003). Second language transfer during third language acquisition. Work. Pap. TESOL Appl. Linguist. 3, 1-21.

Nation, I. S. P. (2001). Learning Vocabulary in Another Language. Cambridge: Cambridge University Press.

Nation, R., and McLaughlin, B. (1986). Novices and experts: an information processing approach to the "good language learner” problem. Appl. Psycholinguist. 7, 41-55.

Newport, E. L., and Aslin, R. N. (2004). Learning at a distance: statistical learning of non-adjacent dependencies. Cogn. Psychol. 48, 127-162.

Osterhout, L., McLaughlin, J., Pitkänen, I., Frenck-Mestre, C., and Molinaro, N. (2006). Novice learners, longitudinal designs, and event-related potentials: a means for exploring the neurocognition of second language processing. Lang. Learn. 56, 199-230.

Perani, D., Abutalebi, J., Paulesu, E., Brambati, S., Scifo, P., Cappa, S. F., and Fazio, F. (2003). The role of age of acquisition and language usage in early, high-proficient bilinguals: an fMRI study during verbal fluency. Hum. Brain Mapp. 19, 170-182.

Prior, A., and MacWhinney, B. (2010). A bilingual advantage in task switching. Biling. (Camb. Engl.) 13, 253-262.

PsychCorp. (1999). Wechsler Abbreviated Scale of Intelligence Manual. San Antonio, TX: Harcourt Assessment

Saffran, J. R., Aslin, R. N., and Newport, E. L. (1996). Statistical learning by 8 -month-old infants. Science 274 1926-1928.

Saffran, J. R., Johnson, E. K., Aslin, R. N., and Newport, E. L. (1999). Statistical learning of tone sequences by human infants and adults. Cognition 70, 27-52.

Sahni, S. D., Seidenberg, M. S., and Saffran, J. R. (2010). Connecting cues: overlapping regularities support cue discovery in infancy. Child Dev. 81 , 727-736.

Salvatierra, J. L., and Rosselli, M. (2011). The effect of bilingualism and age on inhibitory control. Int. J. Biling. 15 , 26-37.

Sanz, C. (2000). Bilingual education enhances third language acquisition evidence from Catalonia. Appl. Psycholinguist. 21, 23-44.

Sebastian-Gallés, N., RodríguezFornells, A., De Diego-Balaguer, R., and Díaz, B. (2006). First- and second-language phonological representations in the mental lexicon. $J$. Cogn. Neurosci. 18, 1277-1291.

Service, E., Simola, M., Metsänheimo, O., and Maury, S. (2002). Bilingual working memory span is affected by language skill. Eur. J. Cogn. Psychol. 14, 383-408.

Simon, J. R., and Small, A. M. (1969). Processing auditory information: interference from an irrelevant cue. J. Appl. Psychol. 53, 433-435.

Soveri, A., Laine, M., Hämäläinen, H., and Hugdahl, K. (2010). Bilingual advantage in attentional control evidence from the forced-attention dichotic listening paradigm. Biling. (Camb. Engl.) 14, 371-378.
Tao, L., Marzecová, A., Taft, M., Asanowicz, D., and Wodniecka, Z (2011). The efficiency of attentional networks in early and late bilinguals: the role of age of acquisition. Front. Psychol. 2:123. doi:10.3389/fpsyg.2011.00123

Theissen, E. D., and Saffran, J. R. (2003). When cues collide: use of stress and statistical cues to word boundaries by 7- to 9-month-old infants. Dev. Psychol. 39, 706-716.

Van Hell, J. G., and Mahn, A. C. (1997). Keyword mnemonics versus rote rehearsal: learning concrete and abstract foreign words by experienced and inexperienced learners. Lang. Learn. 47, 507-546.

Wagner, R. K., Torgesen, J. K., and Rashotte, C. A. (1999). Comprehensive Test of Phonological Processing: CTOPP. Austin, TX: Pro-Ed, Inc.

Weiss, D., Gerfen, C., and Mitchel, A. (2010). Colliding cues in word segmentation: the role of cue strength and general cognitive processes. Lang. Cogn. Process. 25, 402-422.

Conflict of Interest Statement: The authors declare that the research was conducted in the absence of any commercial or financial relationships that could be construed as a potential conflict of interest.

Received: 02 March 2011; accepted: 21 October 2011; published online: 25 November 2011.

Citation: Bartolotti J, Marian V, Schroeder SR and Shook A (2011) Bilingualism and inhibitory control influence statistical learning of novel word forms. Front. Psychology 2:324. doi: 10.3389/fpsyg.2011.00324

This article was submitted to Frontiers in Cognition, a specialty of Frontiers in Psychology.

Copyright (C) 2011 Bartolotti, Marian, Schroeder and Shook. This is an openaccess article distributed under the terms of the Creative Commons Attribution Non Commercial License, which permits use, distribution, and reproduction in other forums, provided the original authors and source are credited. 


\section{APPENDIX}

Table A1 | First and second language knowledge by group.

\begin{tabular}{|c|c|c|c|c|c|c|c|c|c|c|}
\hline & \multicolumn{2}{|c|}{ All participants $(N)$} & \multicolumn{2}{|c|}{ Low bilingual experience $(N)$} & \multicolumn{2}{|c|}{ High bilingual experience ( $N$ ) } & \multicolumn{2}{|c|}{ Weak IC (N) } & \multicolumn{2}{|c|}{ Strong IC (N) } \\
\hline & $\mathbf{L 1}$ & L2 & $\mathbf{L 1}$ & L2 & $\mathbf{L 1}$ & $\mathbf{L 2}$ & $\mathbf{L 1}$ & L2 & L1 & L2 \\
\hline English & 20 & 2 & 10 & 1 & 10 & 1 & 10 & 1 & 10 & 1 \\
\hline Spanish & - & 7 & - & 3 & - & 4 & - & 4 & - & 3 \\
\hline Chinese & 1 & 4 & 1 & 1 & - & 3 & 1 & 2 & - & 2 \\
\hline Korean & 1 & 1 & - & - & 1 & 1 & - & - & 1 & 1 \\
\hline French & - & 1 & - & 1 & - & - & - & 1 & - & - \\
\hline Gujarati & - & 1 & - & - & - & 1 & - & - & - & 1 \\
\hline Tamil & - & 1 & - & - & - & 1 & - & 1 & - & - \\
\hline
\end{tabular}

IC, inhibitory Control; L1, first language; L2, second language. 